九州大学学術情報リポジトリ

Kyushu University Institutional Repository

\title{
Analytical Model for Zinc Uptake by Root System of Thlaspi caerulescens
}

Qian, Xu Dong

Graduate school of Bioresource and Bioenvironmental Science, Kyushu Unviersity

Eguchi, Toshihiko

Biotron Institute, Kyushu University

Yoshida, Satoshi

Biotron Institute, Kyushu University

Chikushi, Jiro

Biotron Institute, Kyushu University

https://doi.org/10.5109/4658

出版情報：九州大学大学院農学研究院紀要. 50 (2)，pp.443-458，2005-10-01. Faculty of Agriculture, Kyushu University

バージョン :

権利関係 : 
J. Fac. Agr., Kyushu Univ., 50 (2), 443-458 (2005)

\title{
Analytical Model for Zinc Uptake by Root System of Thlaspi caerulescens
}

\author{
Xu Dong QIAN ${ }^{1}$, Toshihiko EGUCHI, Satoshi YOSHIDA and Jiro CHIKUSHI*
}

\author{
Biotron Institute, Kyushu University, Hakozaki, 6-10-1, Fukuoka 812-8581, Japan \\ (Received May 2, 2005 and accepted July 26, 2005)
}

\begin{abstract}
To develop future phytoextraction technologies, models describing the process of phytoextraction are necessary. In this paper we have developed an analytical model of zinc uptake by the growing root system of Thlaspi caerulescens, which includes zinc flow by convection and dispersion in soil, the growth of root system, and the total zinc flux to the root. Simulated results indicated that the model could quantitatively describe the zinc uptake process for $T$. caerulescens. Therefore, the model might help us to understand the quantitative characteristics of phytoextraction.
\end{abstract}

\section{INTRODUCTION}

The phenomenon of phytoextraction is performed in a complex plant-soil system. Phytoextraction of soil zinc by using Thlaspi caerulescens is dependent on not only genetic but also environmental characteristics. Zinc movement in the soil is governed by convection and dispersion flow. If the soil cannot supply sufficient zinc to the root surface, the capacity of hyperaccumulator will be limited (Whiting et al., 2003). Moreover, the plant availability and the dynamic movement of zinc in the soil are influenced by physical, chemical and biological properties of the soil (Ernst, 1996; Whiting et al., 2001).

Therefore, in the commercialization of phytoextraction technology, mathematical models are needed to evaluate the economic viability, to predict optimal metal removal rates, and to simulate plant physiological processes with physical, chemical and biological changes in plant-soil systems. Whiting et al. (2003) applied a solute transfer model (Baldwin et al., 1973) to predict that the soil can supply zinc to the root of $T$. caerulescens at a sufficient rate for maximal phytoextraction. This model includes plant parameters like root density and rate of uptake, and it also contains parameters of zinc movement such as effective diffusion coefficient of zinc in soil, zinc buffer power of the soil, water flux from the soil to the root surface, etc. However, the model does not consider the root distribution and morphology of the plant. It has been reported by Schwartz et al. (1999) that the roots of T. caerulescens exhibited high affinity for soil containing zinc with high concentrations. This means the root distribution and morphology of $T$. caerulescens are important factors in phytoextraction which cannot be neglected.

\footnotetext{
1 Biotron Institute, Department of Plant Resource, Graduate School of Bioresource and Bioenvironmental Science, Kyushu University

* Corresponding author (E-mail: chiku2@agr.kyushu-u.ac.jp)
} 
In this study, we developed a zinc uptake model to describe the soil zinc uptake by growing root system of $T$. caerulescens in the zinc phytoextraction.

\section{MODEL DEVELOPMENT}

\section{Root growth model of Thlaspi caerulescens}

Root branching structure develops when roots emerge from the seed, form lateral branches, and from their side. These lateral branches will in turn develop branches of their own. The branching occurs in the middle part of the root since non-branching regions exist near the base and tip of the roots. These non-branching regions develop as a result of root internal hormones, although the exact biochemical mechanism of their formation still remains unknown. Typically, the roots emerging from the seed, the zero order, are thickest in the system, and they connect to the stem of the plant. The higher lateral branch order, the smaller the radius of the branches becomes.

The surface of roots consists of epidermal cells. Some of those epidermal cells form extrusions into the soil, known as root hairs. Root hairs are transformations of the root surface cells and the mechanism of nutrient uptake by them seems to be similar to the uptake at the root surface. However, due to their small radius and high density, they may make a large contribution to the nutrient uptake.

To develop the model of zinc uptake, we need the information of the root size distribution. We assumed that the higher order roots are created by branching from the lower order roots. The frequency of branching, i.e., creation of higher order root, is dependent on the length of the lower order root.

Roots of $T$. caerulescens have typically 3 or 4 orders. The branches which emerge from the seed are called zero order branches, and the rest are called higher order branches. Roots of $T$. caerulescens also have root hairs emerged from the root surface cells. Due to their small radius and high density, root hairs have considerable root surface area and play an important role in zinc uptake. Therefore, the growth of zero order branches, first order branches, second order branches, and root hairs was considered in this study.

The root development of $T$. caerulescens can be described by a simple algebraic model derived by Hackett and Ross (1972), which gives the numbers and lengths of root members of different orders in terms of time:

$$
\begin{aligned}
& N_{0}=1 \\
& N_{1}=R_{0} Q_{1}\left(T-T_{1}\right) \quad T>T_{1} \\
& N_{2}=R_{0} R_{1} Q_{1} Q_{2}\left(T-T_{2}\right)^{2} / 2 \quad T>T_{2} \\
& L_{0}=V_{0}\left(T-T_{0}\right) \quad T>T_{0} \\
& L_{1}=R_{0} Q_{1} V_{1}\left(T-T_{1}\right)^{2} / 2 \quad T>T_{1} \\
& L_{2}=R_{0} R_{1} Q_{1} Q_{2} V_{2}\left(T-T_{2}\right)^{3} / 6 \quad T>T_{2}
\end{aligned}
$$

where $N_{i}\left(i=0,1\right.$, and 2) is the number of root members, $L_{i}(i=0,1$, and 2$)$ is the length of root members, $R_{i}(i=0,1$, and 2$)$ is the rate of extension of the branched region along a root member, $Q_{i}(i=1$ and 2$)$ is the density of branching, $V_{i}(i=0,1$, and 2$)$ is the rate 
of extension of root members, $T$ is the time from initial wetting of the seed, and $T_{i}(i=0$, 1 , and 2) is the time at which the first representative of each order of root appears.

The expressions above may be further simplified by assuming $R_{i}=V_{i}$.

The total number $\left(N_{\mathrm{h}}\right)$ and the total length $\left(L_{\mathrm{h}}\right)$ of root hair on the root can be expressed as:

$$
\begin{aligned}
& N_{\mathrm{h}}=L_{0} Q_{\mathrm{h} 0}+L_{1} Q_{\mathrm{h} 1}+L_{2} Q_{\mathrm{h} 2} \\
& L_{\mathrm{h}}=N_{\mathrm{h}} l_{\mathrm{h}}
\end{aligned}
$$

here $Q_{\mathrm{h} i}$ is the linear density of root hair on the ith order root $(i=0,1$, and 2$)$, and $l_{\mathrm{h}}$ is the length of a single root hair.

Hence, the effective length of each root member in the zinc uptake can be expressed as:

$$
\begin{aligned}
& L_{0 \mathrm{~B}}=\left(L_{0 \mathrm{~A}}+L_{0 \mathrm{~B}}\right) / 2 \\
& L_{1 \mathrm{~B}}=\left[\left(L_{1 \mathrm{~A}}+\left(L_{1 \mathrm{~A}} L_{1 \mathrm{~B}}\right)^{1 / 2}+L_{1 \mathrm{~B}}\right] / 3\right. \\
& L_{2 \mathrm{~B}}=\left[\left(L_{2 \mathrm{~A}}+\left(L^{2}{ }_{2 \mathrm{~A}} L_{2 \mathrm{~B}}+L_{2 \mathrm{~A}} L_{2 \mathrm{~B}}\right)^{1 / 3}+L_{2 \mathrm{~B}}\right] / 4\right.
\end{aligned}
$$

where $L_{i \mathrm{E}}\left(i=0,1\right.$, and 2) is the effective length of root members, $L_{i \mathrm{~B}}(i=0,1$, and 2) is the length of root members before zinc treatment, and $L_{i \mathrm{~A}}(i=0,1$, and 2$)$ is the length of root members after zinc treatment.

The effective length of root hair can be written as:

$$
L_{\mathrm{hE}}=\left(L_{0 \mathrm{E}} Q_{\mathrm{h} 0}+L_{1 \mathrm{E}} Q_{\mathrm{h} 1}+L_{2 \mathrm{E}} Q_{\mathrm{h} 2}\right) l_{\mathrm{h}}
$$

here $Q_{\mathrm{h} i}$ is the linear density of root hair on the ith order root, and $l_{\mathrm{h}}$ is the length of a single root hair $(i=0,1$, and 2$)$.

\section{Zinc transport near root surface}

Zinc uptake by roots can be described as a nutrient uptake model of plant. The nutrient uptake by roots is considered to occur in only liquid phase of the soil. We assumed that the soil is homogeneous, isotropic, and water saturated, and that the changes in the moisture condition are negligible. As in the classical models, the effect of root exudates, microbial activity, mycorrhizae etc. on the plant nutrient uptake and nutrient movement in the soil was neglected. The movement of nutrient to the root surface can take place by convection due to water uptake by the plant, and by dispersion of nutrient ions in the soil pore water. Zinc uptake by a single cylindrical root can be described using the model derived by Nye and Marriott (1969):

$$
\frac{\partial C}{\partial t}=\frac{1}{r} \frac{\partial}{\partial r}\left(r D \frac{\partial C}{\partial r}+\frac{v_{o} r_{o}}{b} C\right)
$$

where $r$ is the radial distance from the root axis, $r_{0}$ is the root radius, $C$ is zinc concentration in soil solution, $v_{0}$ is the inward flux of water at the root surface, $D$ is the dispersion coefficient (considered constant) in the soil, $b$ is the differential buffer power (i.e., $b=\mathrm{d} C_{\mathrm{d}} / \mathrm{d} C_{1}$, where $C_{\mathrm{d}}$ is the total concentration of diffusible solute, $C_{1}$ is the concentration of solute in soil solution.)(Baldwin et al., 1973), and $t$ is time of uptake. 
The initial conditions are:

$$
C=C_{\mathrm{s}}, t=0, r>r_{0}
$$

where $C_{\mathrm{s}}$ is the initial zinc concentration in the soil solution.

Metal ions cannot move freely across the cellular membranes, which are lipophilic structures. Therefore, ion transport into cells must be mediated with membrane proteins having transport functions, generically known as transporters. These transporters are characterized by certain kinetic parameters, such as transport capacity (maximum catalytic rates: $I_{\max }$ ) and affinity for ion (substrate affinities: $K_{\mathrm{m}}$ ). $I_{\max }$ measures the maximum rate of ion transport across the cellular membranes. $K_{\mathrm{m}}$ measures transporter affinity for specific ion and represents the ion concentration in the external solution at which the transport rate equals $I_{\max } / 2$. A low $K_{\mathrm{m}}$ value, high affinity, indicates that high levels of ions are transported into cells, even at low external ion concentration. By studying the kinetic parameters, $K_{\mathrm{m}}$ and $I_{\max }$, insights to specificity and selectivity of the transport system can be gained.

As proved by some researchers, zinc uptake by Thlaspi caerulescens takes place through transporters (Pence et al., 2000; Assunção et al., 2001). It can be described by Michaelis-Menten kinetics:

$$
I=\frac{I_{\max } C_{0}}{K_{\mathrm{m}}+C_{0}}
$$

where $I$ is rate of the root influx, $I_{\max }$ is the maximum influx rate, $K_{\mathrm{m}}$ is the value of the concentration at which $I=I_{\max } / 2, C_{0}$ is the zinc concentration at the root surface.

Eq. (13) is subjected to two boundary conditions as described by Nye and Marriott (1969). The first is:

$$
D b \frac{\partial C}{\partial r}+v_{0} C=\frac{I_{\max } C_{0}}{K_{\mathrm{m}}+C} \text { for } t>0, r=r_{0}
$$

If we assume zinc concentration in soil solution is low, Eq. (16) reduces to:

$$
D b \frac{\partial C}{\partial r}+v_{0} C=k_{\mathrm{m}} C \quad \text { for } \quad t>0, r=r_{0}
$$

where $k_{\mathrm{m}}=I_{\max } / K_{\mathrm{m}}$.

If we assume zinc concentration in soil solution is high, then Eq. (16) reduces to:

$$
D b \frac{\partial C}{\partial r}+v_{0} C=I_{\max } \quad \text { for } \quad t>0, r=r_{0}
$$

The second boundary condition is:

$$
D b \frac{\partial C}{\partial r}+v_{1} C=0 \quad \text { for } \quad t>0, r=r_{1}
$$

where $r_{1}$ is the radius of a cylinder coaxial that is far from the root axis, $v_{1}$ is the inward flux of water at $r_{1}$. Here, it is assumed that no nutrient passes through the outer cylinder wall and yet water is allowed to pass through (Cushman, 1979a). For conservation of 
water,

$$
2 \pi r_{0} v_{0}=2 \pi r_{1} v_{1}
$$

Thus, the outer boundary condition considering inter-root competition for nutrient may be expressed as:

$$
D b \frac{\partial C}{\partial r}+\frac{r_{0}}{r_{1}} v_{0} C=0 \quad \text { for } \quad t>0, r=r_{1} .
$$

The nondimensionalization of variables can be performed following Cushman's (1979a) method:

$$
\begin{aligned}
& w=t\left(D / r_{0}^{2}\right) \\
& z=r / r_{0} \\
& X(z, w)=1-C(r, t) / C \mathrm{~s} \\
& u=-r_{0} v_{0} / 2 D b \\
& p=I_{\max } / k_{\mathrm{m}} C_{\mathrm{s}} \\
& \beta=k_{\mathrm{m}} / v_{0} \\
& a=r_{1} / r_{0}
\end{aligned}
$$

Therefore, Eqs. (13), (14), (17a), (17b), and (18) become:

$$
\begin{aligned}
& \frac{\partial X}{\partial w}= \frac{\partial^{2} X}{\partial z^{2}}+\frac{1}{z}(1-2 \mu) \frac{\partial X}{\partial z} \\
& X=0 \quad \text { for } \quad w=0,1<z<a \\
& \frac{\partial X}{\partial z}=2 \mu(X-1)(1-\beta) \quad \text { for } \quad w>0, z=1 \\
& \frac{\partial X}{\partial z}=2 \mu[(X-1)+\beta p] \quad \text { for } \quad w>0, z=1 \\
& \frac{\partial X}{\partial z}=\frac{2 \mu}{a}(X-1) \quad \text { for } \quad w>0, z=a
\end{aligned}
$$

respectively.

Assuming $X(z, w)$ can be expressed as $X(z, w)=W(w) Z(z)$, thus two ordinary differential equations may be obtained from Eq. (20) :

$$
W^{\prime}+\lambda^{2} W=0
$$

and

$$
Z^{\prime \prime}+\frac{1}{z}(1-2 \mu) Z^{\prime}+\lambda^{2} Z=0
$$

The solutions of Eq. (25) and (26) are: 


$$
W(w)=A_{1} \exp \left(-\lambda^{2} w\right)
$$

and

$$
Z(z)=A_{2} z^{u} J_{u}(\lambda z)+A_{3} z^{u} Y_{u}(\lambda z)
$$

Here $A_{1}, A_{2}, A_{3}$, and $\lambda$ are constants. $J_{u}$ and $Y_{u}$ are Bessel functions of the first and second kind, respectively, which are expressed as:

$$
\begin{aligned}
& J_{u}(\lambda z)=\sum_{k=0}^{\infty} \frac{(-1)^{k}(\lambda z / 2)^{u+2 k}}{k ! \Gamma(u+k+1)} \\
& J_{-u}(\lambda z)=\sum_{k=0}^{\infty} \frac{(-1)^{k}(\lambda z / 2)^{-u+2 k}}{k ! \Gamma(-u+k+1)} \\
& Y_{u}(\lambda z)=\frac{J_{u}(\lambda z) \cos (u \pi)-J_{-u}(\lambda z)}{\sin (u \pi)}
\end{aligned}
$$

where $\Gamma(u+k+1)$ and $\Gamma(-u+k+1)$ are gamma functions. Therefore, the general solution of Eq. (20) can be written as:

$$
X(z, w)=A_{1} \exp \left(-\lambda^{2} w\right)\left[A_{2} z^{u} J_{u}(\lambda z)+A_{3} z^{u} Y_{u}(\lambda z)\right]
$$

As inter-root competition is considered, we can obtain a specific solution $X(z, w)=1$ when $C(r, t)=0$, which means zinc is completely depleted. Hence, Eq. (32) can be expressed as:

$$
X(z, w)=\sum_{n=0}^{\infty} A_{n} z^{u} B_{u}\left(\lambda_{n}, z\right) \exp \left(-\lambda_{n}{ }^{2} w\right)+1
$$

Where

$$
\begin{aligned}
B_{u}\left(\lambda_{n}, z, \beta\right)= & {\left[\lambda_{n} Y_{u-1}\left(\lambda_{n}\right)-2 u(1-\beta) Y_{u}\left(\lambda_{n}\right)\right] J_{u}\left(\lambda_{n} z\right) } \\
& -\left[\lambda_{n} J_{u-1}\left(\lambda_{n}\right)-2 u(1-\beta) J u\left(\lambda_{n}\right)\right] Y_{u}\left(\lambda_{n} z\right)
\end{aligned}
$$

For inter root competition, $\lambda_{n}$ satisfy

$$
\begin{aligned}
& \left.\left[\lambda a J_{u-1}(\lambda a)-2 u J_{u}(\lambda a)\right] \lambda Y_{u-1}(\lambda)-2 u(1-\beta) Y_{u}(\lambda)\right] \\
& -\left[\lambda a Y_{u-1}(\lambda a)-2 u Y_{u}(\lambda a)\right]\left[\lambda J u_{-1}(\lambda)-2 u(1-\beta) J u(\lambda)\right]=0
\end{aligned}
$$

To satisfy the initial condition,

$$
\sum_{n=0}^{\infty} A_{n} z^{u} B_{u}\left(\lambda_{n}, z\right)=-1
$$

is needed. $A_{n}$ can be obtained as: 


$$
A_{n}=-\int_{1}^{a} z^{1-u} B_{u}\left(\lambda_{n}, z\right) \mathrm{d} z / \int_{1}^{a} z B_{u}{ }^{2}\left(\lambda_{n}, z\right) \mathrm{d} z
$$

\section{Total zinc uptake by the root system of Thlaspi caerulescens}

If we assume that all the root members of ith order root have the same radius. The total zinc uptake can be written as:

$$
F_{\text {Total }}=\sum_{i=0}^{2} \int_{T_{\mathrm{s}}}^{T} 2 \pi \rho_{\mathrm{i}} L_{\mathrm{i}}(t) F_{\mathrm{i}}(t) \mathrm{d} t+\int_{T_{\mathrm{s}}}^{T} 2 \pi \rho_{\mathrm{h}} L_{\mathrm{h}}(t) F_{\mathrm{h}}(t) \mathrm{d} t
$$

where $\rho_{i}$ is the radius of the root members of $i$ th order root, $\rho_{\mathrm{h}}$ is the radius of a single root hair, $T$ is the time from initial wetting of the seed, $T_{\mathrm{s}}$ is the time at which the zinc treatment starts, $F_{i}(t)$ is the flux of zinc at the root surface, and $F_{h}(t)$ is the flux of zinc at the root hair surface. $L_{i}(t)$ and $L_{\mathrm{h}}(t)$ are the length of $i$ th order root and the root hair respectively, which are the functions of time ( $i=0,1$, and 2).

From Equation (17a) and (17b), when soil zinc concentration is low, the flux at the root can be written as:

$$
F_{i}(t)=k_{\mathrm{m}} C \quad \text { at } \quad r=r_{0}
$$

and at high soil zinc concentration, it can be

$$
F_{i}(t)=I_{\max } \quad \text { at } \quad r=r_{0}
$$

In nondimensional variables, we can obtain:

$$
\begin{aligned}
& F_{i}(t)=k_{\mathrm{m}} C_{0}[1-X(z, w)] \quad \text { at } \quad z=1 \\
& F_{i}(t)=k_{\mathrm{m}} C_{0} p \quad \text { at } \quad z=1
\end{aligned}
$$

Therefore, when the soil zinc concentration is low, the total flux $F^{\mathrm{L}}$ Total of zinc at root surface of $T$. caerulescens can be expressed as:

$$
\begin{aligned}
F_{\text {Total }}^{\mathrm{n}}=\sum_{i=0}^{2} \frac{2 \pi k_{\mathrm{m}} C_{0} \rho_{i}{ }^{3} L_{i \mathrm{E}}}{D} \int_{w \mathrm{~s}}^{w}\left[1-X_{i}(1, w)\right] \mathrm{d} w \\
+\frac{2 \pi k_{\mathrm{m}} C_{0} \rho_{h}{ }^{3} L_{h \mathrm{E}}}{D} \int_{w \mathrm{~s}}^{w}\left[1-X_{\mathrm{h}}(1, w)\right] \mathrm{d} w
\end{aligned}
$$

and when the soil zinc concentration is high, the total flux $F^{\mathrm{H}}$ Total is written as:

$$
\begin{array}{r}
F_{\text {Total }}^{\mathrm{H}}=\sum_{i=0}^{2} \frac{2 \pi k_{\mathrm{m}} C_{0} \rho_{i}{ }^{3} L_{i \mathrm{E}} \rho_{i}\left(w-w_{\mathrm{s}}\right)}{D} \\
+\frac{2 \pi k_{\mathrm{m}} C_{0} \rho_{\mathrm{h}}{ }^{3} L_{h \mathrm{E}} \rho_{\mathrm{h}}\left(w-w_{\mathrm{s}}\right)}{D}
\end{array}
$$

where $L_{i \mathrm{E}}$ is the effective length of ith order root and $L_{\mathrm{hE}}$ is the effective length of the root 
hair in zinc treatment. $(i=0,1$, and 2$)$

\section{EVALUATION OF THE MODEL}

\section{Measurements of water-soluble zinc concentrations and soil $\mathrm{pH}$ values}

Water-soluble zinc in vermiculite sample was extracted by mixing the samples with deionized water at a vermiculite/water ratio of $1: 8\left(\mathrm{~g} \mathrm{ml}^{-1}\right)$ in $50-\mathrm{mL}$ centrifuge tubes. A 24-hour equilibration was performed at room temperature, with shaking samples (110 oscillations per min) on a horizontal shaker for one hour every 6 hours. Samples were centrifuged (2000 rpm, $15 \mathrm{~min}$ ) and filtered. Zinc concentrations of filtrate were determined using a fluorescent X-ray (FXR) analyzer (EDX-800, Shimadzu) at the Center of Advanced Instrumental Analysis, Kyushu University (Japan), and water-soluble zinc concentrations in vermiculite were calculated. The resulted relationship between water-soluble zinc and total zinc is shown in Fig. 1.

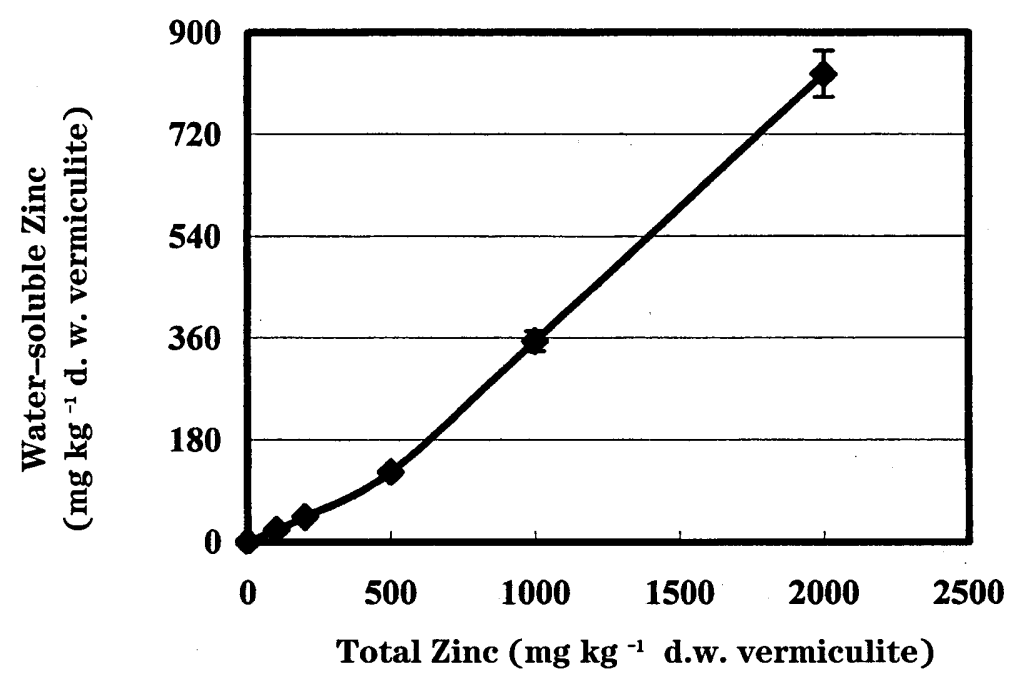

Fig. 1. The relationship between water-soluble zinc and total zinc in vermiculite.

\section{Determination of growth parameters of root system}

T. caerulescens was germinated by placing seeds on the filter paper that was kept moist in the 0.5 concentrated Otsuka nutrient solution [940 of $\mathrm{Ca}\left(\mathrm{NO}_{3}\right)_{2} \cdot 4 \mathrm{H}_{2} \mathrm{O}, 810$ of $\mathrm{KNO}_{3}, 490$ of $\mathrm{MgSO}_{4} \cdot 7 \mathrm{H}_{2} \mathrm{O}, 150$ of $\mathrm{NH}_{4} \mathrm{H}_{2} \mathrm{PO}_{4}, 22.62$ of Fe-EDTA, 2.86 of $\mathrm{H}_{3} \mathrm{BO}_{3}, 1.81$ of $\mathrm{MnCl}_{2} \cdot 4 \mathrm{H}_{2} \mathrm{O}, 0.22$ of $\mathrm{ZnSO}_{4} \cdot 7 \mathrm{H}_{2} \mathrm{O}, 0.08$ of $\mathrm{CuSO}_{4} \cdot 5 \mathrm{H}_{2} \mathrm{O}$, and $0.025 \mathrm{mg} \mathrm{L}^{-1}$ of $\mathrm{Na}_{2} \mathrm{MoO}_{4} \cdot 2 \mathrm{H}_{2} \mathrm{O}$ ]. Fifteen days later, seedlings of $T$. caerulescens were planted for each pot containing $250 \mathrm{~g}$ of vermiculite. Basal fertilizer was also applied by $100 \mathrm{mg} \mathrm{N} \mathrm{kg}^{-1}$ dry vermiculite as 
$\mathrm{NH}_{4} \mathrm{NO}_{3}$, and $80 \mathrm{mg} \mathrm{P} \mathrm{kg}^{-1}$ and $100 \mathrm{mg} \mathrm{K} \mathrm{kg}^{-1}$ as $\mathrm{KH}_{2} \mathrm{PO}_{4}$. Zinc was added as $\mathrm{ZnSO}_{4}$ solution. Zinc treatments were $0,100,200,500,1000$, and $2000 \mathrm{mg} \mathrm{kg}^{-1}$. The vermiculite moisture content was approximately maintained at $1.5 \mathrm{~g} \mathrm{~g}^{-1}$ (water/vermiculite). The $\mathrm{pH}$ value was initially set at 6.00 . The plants were grown in the glass room; in which the temperature was controlled at $25^{\circ} \mathrm{C}$ in the daytime and $20^{\circ} \mathrm{C}$ at night and the relative humidity at $70 \%$. Plants were harvested at $5,10,15,20,25$, and 30 th day after the transplanting. Number and length of root members for respective root order were measured. The result is shown in Table 1.

Table 1. The number and length of root members of Thlaspi caerulescens.

\begin{tabular}{|c|c|c|c|c|c|c|c|c|}
\hline \multirow{2}{*}{\multicolumn{2}{|c|}{ Growth Measurement }} & \multicolumn{7}{|c|}{ Time from Seeding (day) } \\
\hline & & \multirow{2}{*}{$\begin{array}{c}15 \\
1\end{array}$} & \multirow{2}{*}{$\begin{array}{c}20 \\
1 \\
\end{array}$} & \multirow{2}{*}{$\begin{array}{c}25 \\
1\end{array}$} & \multirow{2}{*}{$\begin{array}{c}30 \\
1\end{array}$} & \multirow{2}{*}{$\begin{array}{c}35 \\
1 \\
\end{array}$} & \multirow{2}{*}{$\begin{array}{c}40 \\
1\end{array}$} & \multirow{2}{*}{$\begin{array}{c}45 \\
1 \\
\end{array}$} \\
\hline Zero & Average Number & & & & & & & \\
\hline Order & Average Length (mm) & 39 & 53 & 65 & 80 & 94 & 108 & 123 \\
\hline \multirow{2}{*}{$\begin{array}{l}\text { First } \\
\text { Order }\end{array}$} & Average Number & 8 & 9 & 11 & 14 & 16 & 19 & 21 \\
\hline & Average Length (mm) & 6 & 11 & 15 & 18 & 22 & 26 & 30 \\
\hline \multirow{2}{*}{$\begin{array}{l}\text { Second } \\
\text { Order }\end{array}$} & Average Number & 5 & 11 & 20 & 31 & 46 & 65 & 87 \\
\hline & Average Length (mm) & 3 & 5 & 8 & 10 & 13 & 15 & 17 \\
\hline
\end{tabular}

Eq. (1) to (12) were employed to calculate the rate of extension of the branched region along a root member $\left(R_{i}\right)\left(i=0,1\right.$, and 2), the density of branching $\left(Q_{i}\right)(i=1$ and $2)$, and the rate of extension of root members $\left(V_{i}\right)(i=0,1$, and 2$)$ for different culture periods were determined by using the experimental data. The rate of extension and the density of branch are the functions of time, which were shown in Fig. 2 and Fig. 3. $Q_{1}$ and $Q_{2}$ represent the density of first order and second order respectively. $V_{0}, V_{1}$, and $V_{2}$ are the extension rate of zero order, first order, and second order respectively. Here, we assume that $R_{i}$ is equal to $V_{i}$. T is the time from initial wetting of the seed. The time at which the root of the zero order appeared was the third day. For the first order, it was the fifth day. And for the second order, it was the eighth day.

In the pot culture experiment of $T$. caerulescens, the lengths of root members of different orders were calculated by using the rate of extension of the branched region along a root member, the density of branching, and the rate of extension of root members obtained from Fig. 2 and Fig. 3 (see the dashed lines). The growth parameters are listed in Table 2, where $R_{i}(i=0,1$, and 2$)$ is the rate of extension of the branched region along a root member, $Q_{i}(i=1$ and 2$)$ is the density of branching, and $V_{i}(i=0,1$, and 2$)$ is the rate of extension of root members in pot culture experiment, $T$ is the time from seeding, and $T_{i}$ is the time at which the first representative of each order of root appeared ( $i=0,1$, and 2). The length of a single root hair $\left(l_{\mathrm{h}}\right)$ is assumed to be $1 \mathrm{~mm}$. The numbers of root hair in the unit length (per mm) of zero order, first order, and second order are 62, 47, and 24 respectively. The length and average radius of each order of the plant root system are shown in Table 3. 


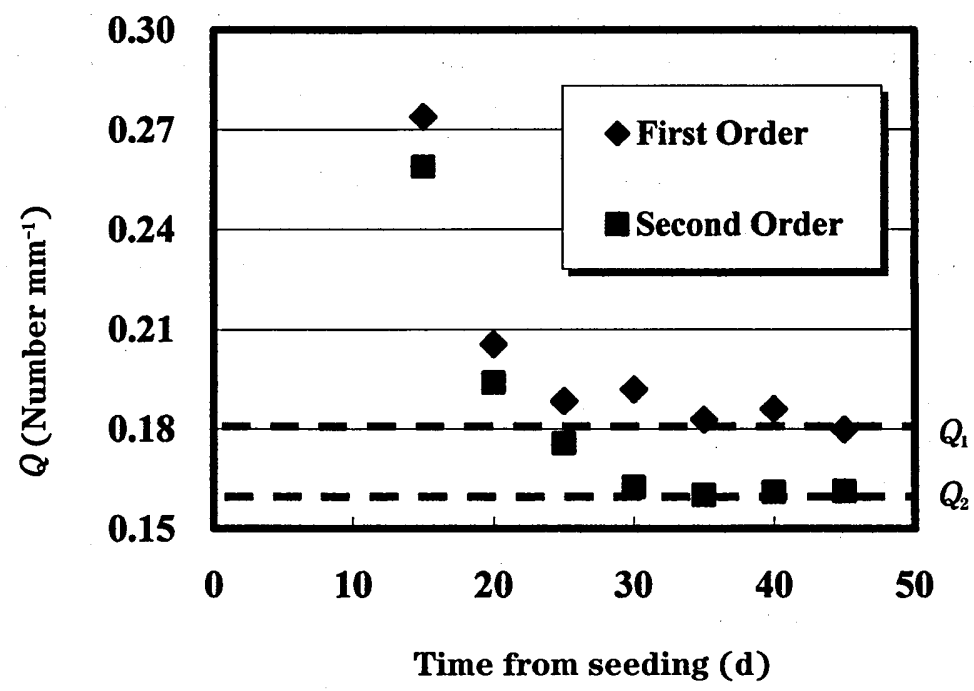

Fig. 2. The density of branching as a function of time. Dashed line indicates the value that is used in the calculation. Diamonds and squares are experimental results.

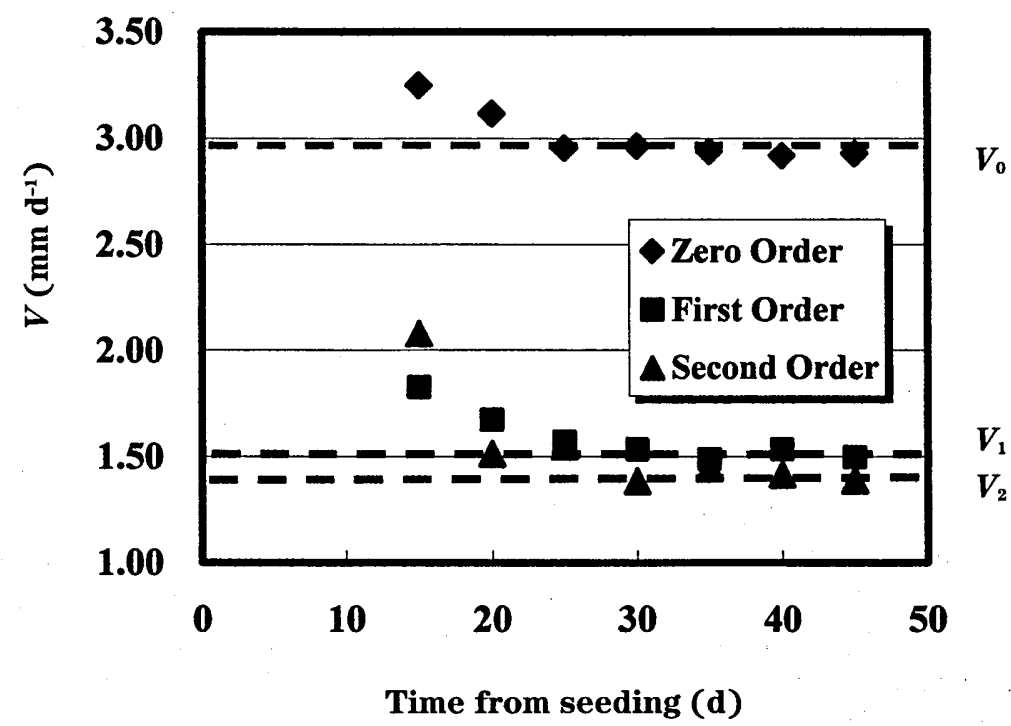

Fig. 3. The extension rate as a function of time.

Dashed line indicates the value that is used in the calculation. Diamonds, squares, and triangles are experimental results. 
Table 2. The growth parameters of the root members of Thlaspi caerulescens.

\begin{tabular}{cccc}
\hline Parameter & $T_{i}($ day $)$ & $Q_{i}\left(\right.$ Number $\left.\mathrm{mm}^{-1}\right)$ & $R_{i}=V_{i}\left(\mathrm{~mm} \mathrm{~d}^{-1}\right)$ \\
\hline Zero Order & 3 & $\#$ & 2.92 \\
First Order & 5 & 0.18 & 1.50 \\
Second Order & 8 & 0.16 & 1.40 \\
\hline
\end{tabular}

Table 3. The length and the radius of each root member of Thlaspi caemulescens.

\begin{tabular}{ccc}
\hline Parameter & $L_{\mathrm{E}}(\mathrm{mm})^{\mathrm{a}}$ & $\rho(\mathrm{mm})$ \\
\hline Zero Order & 269 & 1.8 \\
First Order & 3388 & 1.0 \\
Second Order & 21660 & 0.5 \\
Root Hair & 695754 & $0.01^{\mathrm{b}}$ \\
\hline
\end{tabular}

a. $L_{\mathrm{E}}$ is the effective length and $\rho$ is radius of each root member.

b. The radius of the root hair was assumed as a constant the value of $0.01 \mathrm{~mm}$.

\section{Test of equations}

The total zinc uptake model has been derived by Eq. (42). The solution contains infinite series of the Bessel functions $J_{u}(x)$ and $Y_{u}(x)$, where $\mu=-r_{0} v_{1} / 2 D b$ as defined by Eq. (19d). $J_{-n-1 / 2}$ and $J_{n+1 / 2}$ can be written as products of trigonometric functions (sines and cosines) and powers of $1 / x^{1 / 2}$ (Watson, 1966). And it was given by Mclachlan (1971):

$$
\begin{aligned}
& J_{-n-1 / 2}(x)=(-1)^{n} J_{n+1 / 2}(x) \\
& J_{-1 / 2}(x)=(2 / \pi / x)^{1 / 2} \cos x \\
& Y_{-1 / 2}(x)=(2 / \pi / x)^{1 / 2} \sin x \\
& J_{-3 / 2}(x)=(2 / \pi / x)^{1 / 2}[-\sin x-\cos x / x] \\
& Y_{-3 / 2}(x)=(2 / \pi / x)^{1 / 2}[-\sin x / x+\cos x] \\
& J_{-5 / 2}(x)=(2 / \pi / x)^{1 / 2}\left[(3 / x) \sin x+\left(3 / x^{2}-1\right) \cos x\right] \\
& Y_{-5 / 2}(x)=(2 / \pi / x)^{1 / 2}\left[\left(3 / x^{2}-1\right) \sin x-(3 / x) \cos x\right]
\end{aligned}
$$

and etc.

Assuming $\mu=-1 / 2$, i.e., $r_{0} v_{0} / D b=1$, we can rewritten Eqs. (34), (36), and (33) as:

$$
\begin{aligned}
& B_{u}\left(\lambda_{n}, z\right)=2\left(\pi \lambda_{n} z^{1 / 2}\right)^{-1}\left\{\lambda_{n} \cos \left[\lambda_{n}(1-z)\right]-\beta \sin \left[\lambda_{n}(1-z)\right]\right\} \\
& A_{n}=-\left(\pi \lambda_{n} / 2\right) \int_{1}^{a} z\left\{\lambda_{n} \cos \left[\lambda_{n}(1-z)\right]-\beta \sin \left[\lambda_{n}(1-z)\right]\right\} \mathrm{d} z \mid \\
& \int_{1}^{a}\left\{\lambda_{n} \cos \left[\lambda_{n}(1-z)\right]-\beta \sin \left[\lambda_{n}(1-z)\right]\right\}^{2} \mathrm{~d} z \\
& X(z, w)=(2 / \pi / z) \sum_{n=0}^{\infty} A_{n}\left\{\lambda_{n} \cos \left[\lambda_{n}(1-z)\right]-\beta \sin \left[\lambda_{n}(1-z)\right]\right\} \exp \left(-\lambda_{n}{ }^{2} w\right) / \lambda_{n}+1
\end{aligned}
$$


As $z=1$, Eqs. (46), (47), and (42) can be rewritten as:

$$
\begin{aligned}
& B_{u}\left(\lambda_{n}, 1\right)=2 / \pi \\
& A_{n}=\pi \lambda_{n} / 2
\end{aligned}
$$

And

$$
\begin{aligned}
F_{\text {Total }}=\sum_{i=0}^{2} & \frac{2 \pi k_{\mathrm{m}} C_{0} \rho_{i}{ }^{3} L_{i \mathrm{E}}}{D} \int_{w \mathrm{~s}}^{w}\left[(\pi / w)^{1 / 2} / 2\right] \mathrm{d} w \\
& +\frac{2 \pi k_{\mathrm{m}} C_{0} \rho_{\mathrm{h}}^{3} L_{\mathrm{hE}}}{D} \int_{w \mathrm{~s}}^{w}\left[(\pi / w)^{1 / 2} / 2\right] \mathrm{d} w
\end{aligned}
$$

By using Eq. (19a), we can rewrite respective Eq. (49) and (43) as:

$$
\begin{aligned}
F_{\text {Total }}^{\mathrm{L}}=\sum_{i=0}^{2} & \frac{2 \pi^{3 / 2} k_{\mathrm{m}} C_{0} \rho_{i}{ }^{2} L_{i \mathrm{E}}}{D^{1 / 2}}\left[(T)^{1 / 2}-\left(T_{\mathrm{s}}\right)^{1 / 2}\right] \\
& +\frac{2 \pi^{3 / 2} k_{\mathrm{m}} C_{0} \rho_{\mathrm{h}}{ }^{2} L_{\mathrm{hE}}}{D^{1 / 2}}\left[(T)^{1 / 2}-\left(T_{\mathrm{s}}\right)^{1 / 2}\right]
\end{aligned}
$$

and

$$
\begin{array}{rl}
F_{\text {Total }}^{\mathrm{H}}=\sum_{i=0}^{2} & 2 \pi I_{\max } \rho_{i} L_{i \mathrm{E}}\left(T-T_{\mathrm{s}}\right) \\
& +2 \pi I_{\max } \rho_{\mathrm{h}} L_{\mathrm{hE}}\left(T-T_{\mathrm{s}}\right)
\end{array}
$$

Hence, the total uptake by a single plant can be described by Eq. (50) or (51).

(A) In the case of high concentration of zinc - the test of Eq. (51)

When the zinc concentration of the soil is so high that the soil can supply zinc to the root of $T$. caerulescens at a sufficient rate for maximal phytoextraction, total zinc uptake is dependent on the area of the root surface and the maximum rate of ion transport across the cellular membranes, which is essentially resulted from the genetic factor. In this case, the total zinc uptake by T. caerulescens can be obtained from Eq. (51). Using the data of Lasat et al. (1996) $\left[V_{\max }=0.27 \mu \mathrm{mol} \mathrm{g}^{-1}\right.$ (fresh weight) $\left.\mathrm{h}^{-1}, K_{\mathrm{m}}=8 \mu \mathrm{M}\right]$, we calculated the maximum zinc uptake rate by $T$. caerulescens to be $53.21 \mu \mathrm{mol} \mathrm{d}^{-1} \mathrm{~m}^{-2}$. Here we use this value as the $I_{\max }$. Parameters of the effective length $\left(L_{\mathrm{E}}\right)$ and the radius $(\rho)$ of each root member were shown in Table 3 . Ts and $T$ were given as $35 \mathrm{~d}$ and $125 \mathrm{~d}$, respectively. Hence, from Eq.s (51) we can obtain:

$$
F_{\text {Total }}^{\mathrm{H}}=42.58 \mathrm{mg} \mathrm{pot}^{-1}
$$

Compared with the experimental data (Table 4), this value is larger than the results from the experiments except that in zinc treatment of $2000 \mathrm{mg} \mathrm{kg}^{-1}$. Theoretically, the result from Eq. (51) should be the maximum value of zinc accumulation. The error might be caused by the calculation of root growth parameters, in which only zero order, first order, 
second order, and the root hair have been considered. However, further calculations revealed that the result calculated by Eq. (51) approximated to the average level ( $45.10 \mathrm{mg} \mathrm{pot}^{-1}$ ) of zinc accumulated by T. caerulescens with zinc treatments of $1000 \mathrm{mg}$ $\mathrm{kg}^{-1}$ and $2000 \mathrm{mg} \mathrm{kg}^{-1}$. This means Eq. (51) could be applied to estimate the zinc uptake by $T$. caerulescens when the soil zinc concentration is so high that the zinc influx at the root surface is in the saturate state.

Table 4. The amount of zinc accumulated by Thlaspi caerulescens.

\begin{tabular}{c|cccccc}
\hline Treatment $\left(\mathrm{mg} \mathrm{km}^{-1} \mathrm{~d} . \mathrm{w}.\right)$ & 0 & 100 & 200 & 500 & 1000 & 2000 \\
\hline Total Zinc Uptake $\left(\mathrm{mg} \mathrm{pot}^{-1}\right)$ & 0 & 3.37 & 10.67 & 22.36 & 39.54 & 50.65 \\
\hline
\end{tabular}

\section{(B) In the case of low concentration of zinc - the test of Eq. (50)}

Zinc uptake by $T$. caerulescens is usually limited by the zinc supply of the soil, especially when the soil zinc concentration is low. In this case, total zinc uptake of the plant is not only dependent to the genetic factors, but also affected by the soil characteristics. In Eq. (50), both plant factor and medium factor have been considered. By using the same data of Lasat et al. (1996), as shown in (A), we can calculate $k_{\mathrm{m}}$ by the equation $k_{\mathrm{m}}=I_{\max } / K_{\mathrm{m}}$. Hence, the value of $k_{\mathrm{m}}$ is $0.00665 \mathrm{~m} \mathrm{~d}^{-1}$. We used the value of Shuman (1980) $\left(0.311 \times 10^{-8} \mathrm{~m} \mathrm{~d}^{-1}\right)$ as the dispersion coefficient of zinc $(D)$, which had also been used by Whiting et al. (2003). We did not determine $C_{0}$ in Eq. (50), which is the zinc concentration at the root surface. By using the result calculated in the case of high concentration of zinc [Eq. (52)] and the data in Table 4, we obtained the zinc concentration in vermiculite $C_{\text {ws }}$ of $1273.63 \mathrm{mg} \mathrm{km}^{-1}$ d.w. vermiculite when the zinc influx at the root surface was in the saturate state. It can be assumed that $C_{0}$ is dependent on the water-soluble zinc in the vermiculite. Thus, we calculated $C_{0}$ as following:

$$
C_{0}=C_{\mathrm{s}} C_{\mathrm{w}} / C_{\mathrm{ws}}
$$

where $C_{\mathrm{s}}$ is the root surface concentration of zinc at which the zinc influx is in the saturate state, a value of $27 \mu \mathrm{M}$ was used (Whiting et al., 2003); $C_{\mathrm{w}}$ is the concentration of water-soluble zinc; and $C_{\mathrm{ws}}$ is the zinc concentration in vermiculite at which the zinc influx is in the saturate state (Fig. 1). Parameters of the effective length $\left(L_{\mathrm{E}}\right)$ and the radius $(\rho)$ of each root member are shown in Table 3. $T_{\mathrm{s}}$ and $T$ were given as $35 \mathrm{~d}$ and $125 \mathrm{~d}$, respectively. Figure 4 shows the results obtained from the calculation and the experiment.

It is clear that there is an agreement between the results calculated by Eq. (50) and the experimental data at low soil zinc concentrations, while the errors are very large when we calculate the total zinc uptake of the plant by using Eq. (50) at high zinc concentration. This means Eq. (50) is suitable for predicting the total zinc uptake by $T$. caerulescens at relative low zinc concentrations.

\section{DISSCUSSION}

In this study, we have developed a model of zinc uptake by the growing root system 


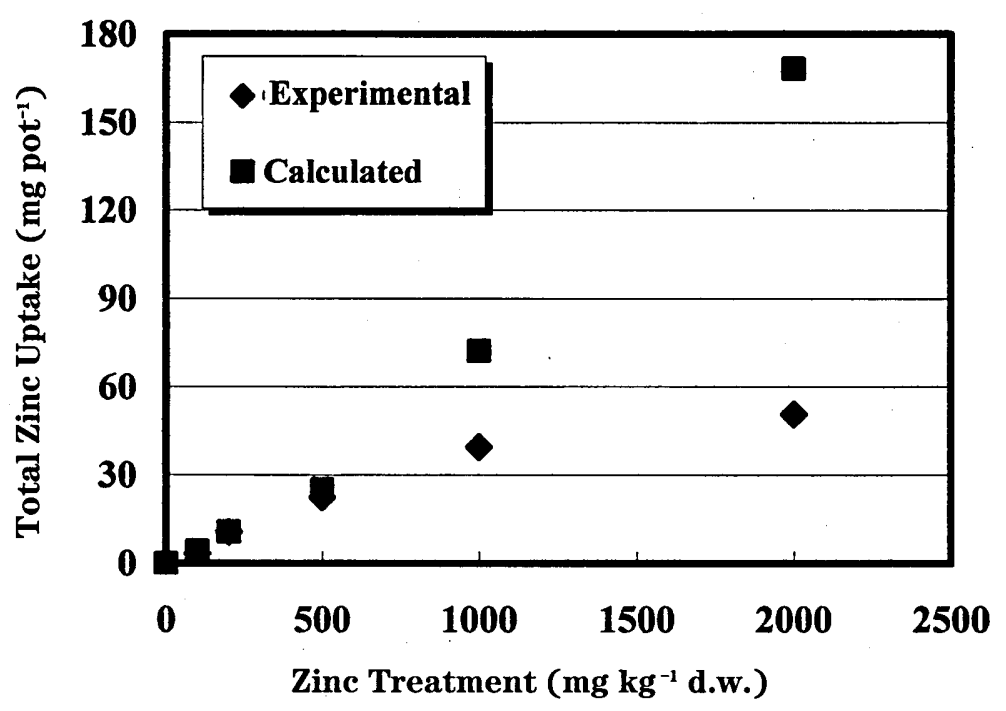

Fig. 4. Total zinc uptake at $125^{\text {th }}$ day after seeding. The values were obtained from the experiments and calculation [Eq. (50)].

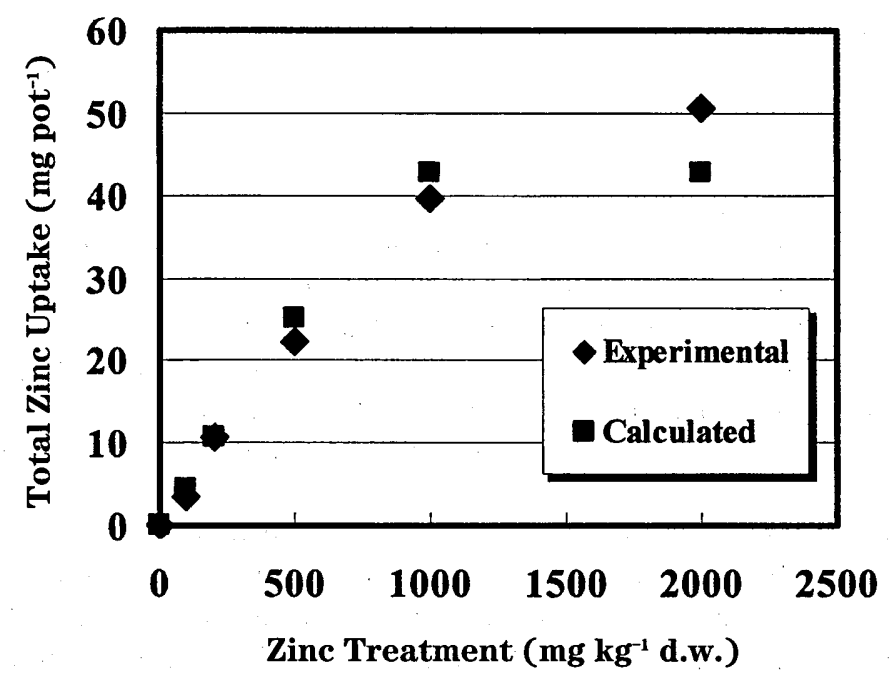

Fig. 5. Total zinc uptake at $125^{\text {th }}$ day after seeding. The values were obtained from the experiments and the calculations [Eq. (50) and (51)]. 
of $T$. caerulescens and derived the computer solutions. The model includes soil zinc supply by diffusion and mass flow, the growth of root system, and the total zinc flux to the root. Tested against the experimental data, the model has given results in close agreement (Fig. 5).

For the calculated data in Figure 5, we used the results obtained from Eq. (50) in the case of relatively low concentrations of soil zinc $\left(\leq 500 \mathrm{mg} \mathrm{kg}^{-1}\right.$ d.w.), while at relatively high concentrations of soil zinc ( $>500 \mathrm{mg} \mathrm{kg}^{-1}$ d.w.), the value calculated by Eq. ( 51 ) was used. The calculation error appeared in the case of high zinc concentrations. It might be caused by the calculation of growth parameters, in which less root orders were taken into account. Therefore, we should improve the evaluation method of root order for the effective use of Eq. (51).

Although the error exists, this model could be useful to simulate the zinc uptake by a growing root system of $T$. caerulescens, especially when the soil zinc concentrations are relatively low. The model can quantitatively describe the zinc accumulation in the growing processes in T. caerulescens, which is controlled by not only the genetic but also the environmental factors. The model is also helpful to predict the total zinc uptake by $T$. caerulescens in different zinc concentrations in soil. In addition, because relationships among the soil zinc supply, the growth of root system, and the total zinc flux to the root are considered, this model might be employed to optimize the future phytoextraction technologies.

\section{REFERENCES}

Assunção, A. G. L., P. De Costa Martins, S. De Folter, R. Vooijs, H. Schat and M. G. M. Aarts 2001 Elevated expression of metal transporter gene in three accessions of the metal hyperaccumulator Thlaspi caerulescens. Plant Cell Environ., 24: 217-226

Baldwin, J. P., P. H. Nye and P. B. Tinker 1973 Uptake of solutes by multiple root systems from soil. III. A model for calculating the solute uptake by a randomly dispersed root system developing in a finite volume of soil. Plant Soil, 38: $621-635$

Brown, S. L., R. L. Chaney, J. S. Angle and A. J. Baker 1994 Phytoremediation potential of Thlaspi caerulescens and bladder campion for zinc- and cadmium-contaminated soil. J. Environ. Qual., 23: $1151-1157$

Cushman, J. H. 1979a An analytical solution for transport near surface for low initial concentration: I. Equations development. Soil Sci. Soc. Am. J., 43: 1087-1090

Cushman, J. H. 1979b An analytical solution for transport near surface for low initial concentration: II. Application. Soil Sci. Soc. Am. J., 43: 1090-1095

Claassen, N. and S. A. Barber 1974 A method for characterizing the relation between nutrient concentration and flux into roots of intact plants. Plant Physiol., 54: 564-568

Ebbs, S. D., M. M. Lasat, D. J. Brady, J. Cornish, R. Gordon and L. V. Kochian 1997 Phytoextraction of cadmium and zinc from a contaminated soil. J. Environ. Qual., 26: 1424-1430

Ernst, W. H. O. 1996 Bioavailability of heavy metals and decontamination of soils by plants. Appl. Geochem., 11: 163-167

Glass, D. J. 2000 Economic potential of phytoremediation. In "Phytoremediation of Toxic Metals Using Plants to Clean Up the Environment", ed. by I. Raskin and B. D. Ensley, John Wiley \& Sons, Inc., New York, pp. 15-33

Hackett, C. and D. A. Ross 1972 A model of the extension and branching of seminal root of barley, and its use in studying relations between root dimensions. I. The model. Aust. J. Biol. Sci., 25: 669-679

Knight, B., F. J. Zhao, S. P. McGrath and Z. G. Shen 1997 Zinc and cadmium uptake by the hyperaccumulator Thlaspi caerulescens in contaminated soils and its effects on the concentration and chemical speciation of metals in soil solution. Plant Soil, 197: 71-78 
Küpper, H., F. J. Zhao and S. P. McGrath 1999 Cellular compartmentation of zinc in leaves of the hyperaccumulator Thlaspi caerulescens. Plant Physiol., 119: 305-311

Lasat, M. M., A. J. M. Baker and L. V. Kochian 1996 Physiological characterization of root $\mathrm{Zn}^{2+}$ absorption and translocation to shoots in $\mathrm{Zn}$ hyperaccumulator and nonaccumulator species of Thlaspi. Plant Physiol., 112: 1715-1722

Lasat, M. M., A. J. M. Baker and L. V. Kochian 1998 Altered Zn compartmentation in the root symplasm and stimulated $\mathrm{Zn}$ absorption into the leaf as mechanisms involved in $\mathrm{Zn}$ hyperaccumulation in Thlaspi caerulescens. Plant Physiol., 118: 875-883

Lasat, M. M., N. S. Pence, D. F. Garvin, S. D. Ebbs and L. V. Kochian 2000 Molecular physiology of zinc transport in the Zn hyperaccumulator Thlaspi caerulescens. J. Exp. Bot., 51: 71-79

Mclachlan, N. W. 1971 Bessel Functions for Engineers. Oxford Univ. Press, London (England), pp. 161

Nye, P. H. and F. H. C. Marriott 1969 Theoretical study of the distribution of substances around roots resulting from simultaneous of diffusion and mass flow. Plant Soil, 3: 459-472

Pence, N. S., P. B. Larsen, S. D. Ebbs, D. L. D. Letham, M. M. Lasat, D. F. Garvin, D. Eide and L. V. Kochian 2000 The molecular physiology of heavy metal transport in the $\mathrm{Zn} / \mathrm{Cd}$ hyperaccumulator Thlaspi caerulescens. Proc. Natl. Acad. Sci. USA, 97: 4956-4960

Reeves, R. D. and A. J. M. Baker 2000 Metal-accumulating plants. In "Phytoremediation of Toxic Metals - Using Plants to Clean Up the Environment", ed. by I. Raskin and B. D. Ensley, John Wiley \& Sons, Inc., New York, pp. 193-229

Schwartz, C., J. L. More, S. Saumier, S. N. Whiting and A. J. M. Baker 1999 Root development of the zinc-hyperaccumulator plant Thlaspi caerulescens as affected by metal origin, content and localization in soil. Plant soil, 208: 103-115

Shuman, L. M. 1980 Zinc in soils. In "Zinc in The Environment, Part I: Ecological Cycling", ed. by J. O. Nriagu, John Wiley \& Sons, Inc., London (England)

Watson, G. N. 1966 A Treatise on The Theory of Bessel Functions. Univ. Press, Cambridge (England), pp. 53-55

Whiting, S. N., M. P. De Souza and N. Terry 2001 Rhizosphere bacteria mobilize Zn for hyperaccumulation by Thlaspi caerulescens. Environ. Sci. Technol., 35: 3144-3150

Whiting, S. N., M. R. Broadley and P. J. White 2003 Applying a solute transfer model to phytoextraction: Zinc acquisition by Thlaspi caerulescens. Plant Soil, 249: 45-56

Zayed, A., E. Pilon-Smits, M. deSouza, Z. Q. Lin and N. Terry 2000 Remediation of selenium-polluted soils and waters by phytoremediation. In "Phytoremediation of Contaminated Soil and Water", ed. by N. Terry and G. Bañuelos, Lewis Publishers, Boca Raton, pp. 61-83 